\title{
Periodic Migrainous Neuralgia
}

\author{
JOHN I. BALLA,* M.B., M.R.C.P.ED. ; JOHN N. WALTON, † M.D., F.R.C.P.
}

Brit. med. F., 1964, 1, 219-221

Periodic migrainous neuralgia is a clearly defined syndrome and excellent descriptions of it have been given by a number of authors (Harris, 1926, 1936 ; Horton et al., 1939 ; Horton, 1941 ; Ekbom, 1947 ; Kunkle et al., 1952 ; Symonds, 1956 ; Bickerstaff, 1959). Its clinical features are usually so characteristic that its diagnosis should present no more difficulty than that of trigeminal neuralgia or classical migraine. Various treatments have been advised in the past, and, in particular, Ekbom (1947), Symonds (1956), and Bickerstaff (1959) have described their experience with prophylactic ergotamine preparations.

Bickerstaff (1959) suggested that the syndrome was well defined but not widely recognized and that it is often misdiagnosed. He suggested that by describing it in a medical journal with a wide circulation it should become better known and many of the diagnostic difficulties would disappear.

We discovered that in our patients the average time from onset of symptoms to diagnosis was 6.5 years; hence it is clear that no remarkable change has occurred in the speed of diagnosis since Bickerstaff's paper appeared, and we therefore decided to review our own experience. We have done this in two ways: first, we give a brief review of the clinical picture as we have seen it, and then the results of treatment are reviewed.

The best description of the essential features of the syndrome was given by Sir Charles Symonds (1956). We can do no better than quote from this classic paper, which appeared under the title, "A Particular Variety of Headache" ". . . occurrence of paroxysms of headache, that is to say, pain of sudden onset and transitory duration, which occur in bouts lasting as a rule for several weeks with long intervals of perfect freedom. In the paroxysm the pain is felt mainly in the supra-orbital region or in and behind the eye, though it may spread beyond this region. It is, however, strictly unilateral. It is of agonizing severity, but very rarely lasts longer than two hours and often less. During a bout there is usually at least one paroxysm in each twenty-four hours; there may be more. In the intervals between paroxysms there is complete relief. The bout having ended, there is no further complaint of headache until the occurrence of the next bout after an interval of freedom, which is rarely less than six months and may be several years. No local cause for the pain is to be discovered. . .."

\section{Material and Methods}

We have followed up all the cases of periodic migrainous neuralgia seen in the neurological out-patient department of the Newcastle General Hospital and of the Royal Victoria Infirmary, Newcastle upon Tyne, over a five-year period. Twenty-eight such cases were seen during this period, whereas in the same period 399 cases of migraine were seen. The period of follow-up varied from one month to five years, with an average of 2.5 years. We were unable to trace four patients.

\section{Clinical Picture}

There were 22 males and 6 females in the series, a strong male preponderance. The age distribution (Table I) was quite variable, the youngest patient being 12 and the oldest 61 at the onset of the neuralgia. The earliest age at which the diagnosis was made was 15 and the oldest 75. Most patients had their first symptoms between the ages of 20 and 40 .

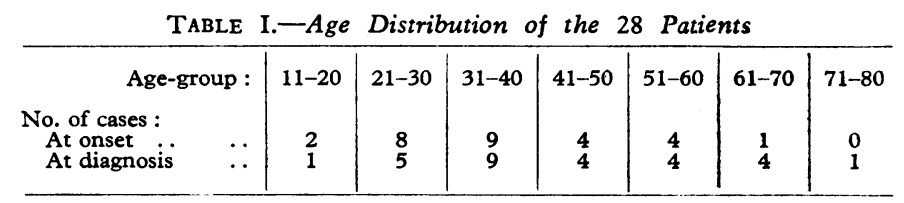

Description of Pain.-The pain was usually clear-cut, and it was interesting how of ten the patients used superlative terms in their descriptions. It was described as throbbing, burning, or boring and extremely severe. Most patients stated that they never had any pain as severe as the pain of these attacks. It quickly increased in severity after the onset, and after remaining constant for a variable period showed a fairly rapid decline. Its location was in or around one eye, and often there was some spread into the temple or on to the side of the face. Localization was always clearly defined and consistent in the same individual. In all cases the pain recurred on the same side of the face, but in three patients it occasionally spread to the opposite side.

Associated Features.-Most commonly these took the form of watering of the affected eye, which often appeared red. Frequently the nostril on the corresponding side was blocked but started to run just before the pain regressed. Occasionally the patients complained of nausea, but vomiting was rare; sometimes there was tenderness or even swelling of the face on the affected side. Other associated features are listed in Table II.

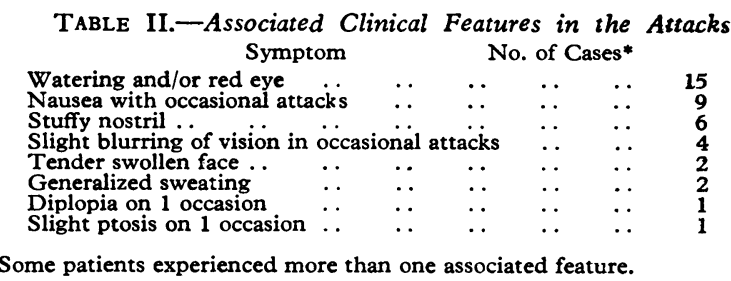

Periodicity.-Two terms are used in this context. An " attack" refers to the actual paroxysm of pain, while a "bout" refers to a period of time when attacks occur regularly, usually at least once a day. The duration of an attack varied from 15 minutes to four hours, usually from half to one hour. A remarkable feature of the attacks was their regularity, and many patients stated that they could set the clock by their appearance at the same time day by day. Often the pain would waken the patient in the early hours of the morning. Most patients had one attack a day, but some had two to five. Bouts lasted from one week to four months in our cases, and during this period headaches would occur every day. Towards the end of the bout they would usually become irregular and would then stop completely. Bouts occurred once or twice a year and in some patients they occurred with a seasonal incidence. Intervals of freedom were sometimes of several years' duration, and one

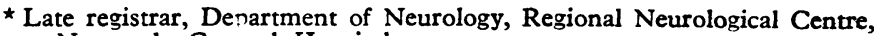
Newcastle General Hospital † Neurologist, Regional Neurological Centre, Newcastle General Hospital.
} 
patient had two bouts separated by an interval of 11 years. Two patients differed slightly from the others. Their headaches still occurred in bouts, and during these periods they had severe attacks three to five times a day. Between the bouts the headaches did not disappear completely, but continued to occur daily, usually in a milder form and generally at the same time of day. In one patient the headaches had been occurring daily for 18 months, and in another for six years.

Relationship to Migraine.-One patient had migraine when he was a schoolboy; this later ceased and was replaced by typical periodic migrainous neuralgia.

Family History.-Three patients had relatives who had migraine, and one patient had a relative who, in retrospect, certainly had periodic migrainous neuralgia.

Diagnosis.-Most patients had their symptoms for long periods before a diagnosis was made. The average length of time for a diagnosis to be made was 6.5 years, and it varied from 25 years in one case to one month in another. Only one patient was referred to the neurological clinic with the correct diagnosis. Two patients had had dental treatment before the diagnosis was made. Four patients were treated for sinusitis. In three cases a diagnosis of trigeminal neuralgia was made, and in 19 cases the headaches were thought to be either migrainous or of the tension variety.

\section{Treatment}

Symonds (1956) and Bickerstaff (1959) reported that the attacks of pain in patients with this condition could be prevented by the administration of one, two, or occasionally three daily injections of $0.5 \mathrm{mg}$. of ergotamine tartrate, and most patients were taught to give their own injections. Several years previously Ekbom (1947) had found that oral ergotamine was of prophylactic value, and we therefore decided to give oral treatment to our patients and to prescribe parenteral ergotamine only if the oral route was ineffective.

Eight patients in our series did not receive treatment in the form of prophylactic ergotamine preparations because they were seen after their last bout, and none of them returned to the clinic to report that another bout was beginning. Three of these were lost in the follow-up. Of these eight cases, most had received ergotamine preparations at the beginning of an attack, and all reported shortening of the duration of the attack but without complete relief.

Twenty patients received prophylactic ergotamine preparations. They were all prescribed "migril" tablets (ergotamine tartrate $2 \mathrm{mg}$., cyclizine hydrochloride $50 \mathrm{mg}$., caffeine $100 \mathrm{mg}$. per tablet). The tablets were taken regularly two or three times a day and not at the beginning of an attack. If the attacks occurred at regular times of the day-for instance, in the early hours of the morning - then in some patients an additional migril tablet was given a few hours prior to the onset of the expected headache. The results are summarized in Table III. It will be seen that all patients received some relief. In six patients, though the relief was not complete, it was substantial. They all stated that the headaches became shorter and less severe. Two of these patients had the chronic form of migrainous neuralgia with attacks going on between their bouts. Both were also treated with subcutaneous ergotamine tartrate injections, and though they received more benefit from this than from the migril tablets they did not obtain complete relief. Ergot

\footnotetext{
TABLE III.-Summary of Results of Treatment with Prophylactic Migril in 20 Cases

Complete or almost complete relief

Significant but incomplete relief

No relief

- One case lost for follow-up. 6 (2 imded to methysergide) amine iniections and also on methysergide)
}

preparations administered in suppository form were alsc unsuccessful. Both patients were then given methysergide (" deseril") when seen in a severe bout. The bout was cut short in each case after the administration of $6 \mathrm{mg}$. of methysergide a day, but the milder daily attacks continued.

Fourteen patients obtained complete relief or noted that they had only occasional twinges of headache which did not worry them particularly. In two of these patients migril lost its effect after three months in one case and after several months in the other. One of these was treated with methysergide $6 \mathrm{mg}$. a day, and this gave immediate and complete relief from the headaches. or with injections of ergotamine tartrate $(0.5 \mathrm{mg}$. subcutaneously at night or twice daily) were told to begin the treatment immediately a bout began and to continue with regular medication for a period corresponding to the duration of an average bout. Usually it was then possible to withdraw treatment without any return of pain, but if attacks recurred the treatment was continued for a further week or two until no relapse occurred after withdrawal. Then, as a rule, treatment was not given until the next bout began.

Possible complications were noted in only three patients: one noticed Raynaud's phenomenon affecting the fingers, one complained of irritability, and one complained of depression. Since the latter two symptoms are non-specific it is difficult to know whether these were side-effects of the treatment.

At the follow-up examination it was noted that among the 14 patients who obtained complete relief with migril there were four who did not carry on with it in all their bouts. In most cases the reason was that the patient's general practitioner did not prescribe it again, but one patient stated that he was " simply tired of taking tablets."

\section{Discussion}

The clinical picture as we saw it was identical with the descriptions given by others. It is therefore somewhat surprising that the average period between the time of onset and diagnosis was still six and a half years in our series. We feel that the reason is that the syndrome is still not sufficiently well recognized and that descriptions occurring in many standard textbooks are too indefinite or brief. Another possible reason suggested by Symonds (1956) and quoted by Bickerstaff (1959) is that this syndrome in the past has been described under a large variety of names. Sluder (1908) referred to the syndrome under the title of sphenopalatine ganglion neuralgia. It was discussed under the same name by Eagle (1942). Harris (1926) described it under the heading, "ciliary migrainous neuralgia." Vail (1932) gave the syndrome the title of vidian neuralgia. Harris (1936) was the first to refer to it as migrainous neuralgia. Horton et al. (1939) called it erythromelalgia of the head, and Horton (1941) renamed it histaminic cephalgia. It was later referred to as petrosal neuralgia (Gardner et al., 1947) and as cluster headaches (Kunkle et al., 1952). While many of the descriptions given by these authors do not present a complete picture of this syndrome, it is our view that they would all be embraced by it.

We feel that early diagnosis is particularly important, because this is an extremely disabling condition and it is responsive to treatment. As can be seen, most patients respond to migril without any significant side-effects, and those who did not respond do well with prophylactic subcutaneous ergotamine tartrate. Recently good reports have appeared on the use of methysergide (Lance et al., 1963 ; Friedman, 1963). We were also impressed by the results with this drug in the few patients to whom we had an opportunity to give it. In future, therefore, if we find that migril is ineffective, we feel that methysergide should be the second line of attack.

We have no reason to believe that other proprietary ergotamine preparations would not be equally as effective as migril ;
The patients who responded to treatment either with migril 
Ekbom (1947) using "gynergen" ${ }_{1}$ reported results similar to our own. It has been our impression that gastro-intestinal side-effects were less riarked with migril than with other preparations, but we have no statistically valid evidence to support this view.

We are unable to throw any light on the aetiology of this condition. We see no reason why it should be attributed to histamine allergy and it is also difficult to relate it to migraine. In our cases a family history of migraine was rarely obtained, and this would be unexpected if this condition was indeed a variant of the migraine syndrome in which a positive family history is the rule rather than the exception. The age and sex distribution is also somewhat different from that of migraine, many of our patients having had their first symptoms in their forties. Though these are only two facets of the clinical picture, they may be of possible significance in distinguishing this syndrome from migraine.

\section{Summary}

Twenty-eight cases of periodic migrainous neuralgia are reviewed. The clinical picture is described. The average time which elapsed between the onset of symptoms and accurate

"Known in Great Britain as " femergen." diagnosis was 6.5 years. Our experiences of treatment using prophylactic migril in 20 patients are discussed. In 14 the response was satisfactory and in six relief was only slight. Two of these patients showed further improvement on prophylactic ergotamine injections. Three patients who failed to respond to oral ergotamine or relapsed responded to methysergide. A plea is made for early diagnosis in this eminently treatable condition.

We are grateful to Dr. Henry Miller for allowing us to review a number of patients who were under his care.

\section{REFERENCES}

Bickerstaff, E. R. (1959). Lancet, 1, 1069

Eagle, W. W. (1942). Arch. Otolaryng., 35, 66.

Ekbom, K. A. (1947). Acta psychiat. (Kbh.), Suppl. No. 46, p. 106. Friedman, A. P. (1963). Neurology (Minneap.), 13, No. 3, Pt. 2, p. 27. Gardner, W. J., Stowell, A., and Dutlinger, R. (1947). F. Neurosurg., 4, 97.

Harris, W. (1926). Neuritis and Neuralgia. Oxford Publications, London. (1936). Brit. med. F., 1, 457.

Horton. B. T. (1941). F. Amer. med. Ass., 116, 377.

MacLean, A. R., and Craig, W. McK. (1939). Proc. Mayo Clin., 14, 257.

Kunkle, E. C., Pfeiffer, J. B., jun., Wilhoit, W. M., and Hamrick, L. W., jun. (1952). Trans. Amer. neurol. Ass., 77, 240.

Lance, J. W., Fine, R. D., and Curran, D. A. (1963). Med. F. Aust., 1, 814 .

Sluder, G. (1908). N.Y. Med. F., 87, 989.

Vail, H. H. (1932). Ann. Otol.'(St. Louis), 41, 837.

\title{
Clinical Trial of Inhaled Ergotamine Tartrate in Migraine
}

\author{
J. CROOKS,* M.D., F.R.C.P.ED., M.R.C.P., M.R.C.P.GLASG. ; S. A. STEPHEN, † M.B., CH.B., M.R.C.P.ED. \\ W. BRASS, $\ddagger$ M.A.
}

Brit. med.F., 1964, 1, 221-224

Ergotamine tartrate has been the drug of choice for the symptomatic treatment of migraine for many years (Brock, et al., 1934), and the vasoconstrictive action which is the basis of its use was clearly demonstrated by Graham and Wolff (1937). Unfortunately ergotamine given orally has been shown to be less effective than when given by the parenteral or rectal route (Lennox and von Storch, 1935 ; Tunis and Wolff, 1953 ; Greene, 1959). Because the practical difficulties associated with ergotamine injections and suppositories limit their use, alternative routes of administration have been sought and a formulation of ergotamine tartrate suitable for oral inhalation (" medihaler-ergotamine") has recently been devised. Although a number of workers from other countries have reported favourably on its use (Finch, 1960 ; Graham et al., 1960 ; Blumenthal and Fuchs, 1961 ; Sutherland and Eadie, 1961 ; DalsgaardNielsen, 1961) their opinions were, in the main, based on uncontrolled observations. The present paper gives the results of a clinical trial of inhaled ergotamine tartrate in the treatment of migraine in which the therapeutic effectiveness of inhalation has been compared with that of the drug given sublingually. The trial was designed to solve the problem posed by a comparison of two different forms of administration of the same drug, as measured by a highly subjective response, by the use of a "double-blind" sequential procedure.

Selection of Patients.-Patients were accepted for inclusion in the trial if they satisfied the following criteria: (1) the duration of complaint of episodic headache had to exceed two years; (2) a family history of episodic headache had to be present; (3) the patient had to have on average two or more attaclss of headache monthly ; (4) the headache had to have a unilateral element ; (5) one or more of the following symptoms had to be associated with the headache; nausea, vomiting, photophobia, diplopia, scotomata, blurring of vision, fortification spectra, paraesthesiae ; and (6) physical signs of neurological disease had to be absent.

Procedure for Inhalation of Ergotamine Tartrate.-A convenient portable apparatus for the self-administration of micronized ergotamine tartrate suspended in an inert aerosol propellant (medihaler-ergotamine) was used. The device was calibrated to deliver a fixed dose of $0.36 \mathrm{mg}$. of ergotamine tartrate per single inhalation. Each patient was taught how to use the device and given both verbal and written instructions to take one inhalation as soon as possible after the onset of a headache, with further single inhalations every 5 to 10 minutes until the headache had gone or a maximum of five inhalations had been reached. The procedure was not to be repeated within 24 hours. The maximum dose of ergotamine tartrate which could be taken during the first hour of an attack was thus $1.8 \mathrm{mg}$.

Procedure for the Sublingual Administration of Ergotamine Tartrate.-Tablets containing $1 \mathrm{mg}$. of ergotamine tartrate were used. Each patient was instructed to place one tablet beneath the tongue as soon as possible after the onset of the headache and to allow the tablet to dissolve. The average dissolution time of the tablets was five minutes. If the headache had not gone within half an hour another tablet was to be taken. No

\footnotetext{
* Senior Lecturer, Department of Materia Medica and Therapeutics,
University of Aberdeen.

† Late Senior Registrar, Aberdeen Royal Infirmary.

¥ Senior Lecturer in Statistics, Department of Statistics, University of Aberdeen.
} 